$\begin{array}{cc}\text { ACADEMIA ROMÂNĂ } & \text { Rev. Roum. Chim., } \\ \text { 2019, 64(11), 949-963 } \\ \text { Revue Roumaine de Chimie } \\ \text { http://web.icf.ro/rrch/ }\end{array}$

\title{
SYNTHESIS AND CHARACTERIZATION \\ OF POLY(ACRYLIC ACID-CO-ACRYLAMIDE)-SAWDUST COMPOSITE FOR THE ADSORPTIVE REMOVAL OF Cd(II) AND Pb(II) FROM AQUEOUS SOLUTIONS
}

\author{
Abdul Qayyum KHAN, ${ }^{\mathrm{a}}$ Ata Ur RAHMAN,${ }^{\mathrm{a}^{*}}$ Muhammad YASEEN, ${ }^{\mathrm{a}}$ Haroon Ur RASHID, \\ Mahmood IQBAL ${ }^{c}$ and Mushtaq Ur REHMAN ${ }^{c}$
}

${ }^{a}$ Institute of Chemical Sciences, University of Peshawar, 25120, Peshawar, KP, Pakistan

${ }^{b}$ Department of chemistry, Sarhad University of Science and Information Technology, Peshawar, KP, Pakistan

${ }^{\mathrm{c}}$ Pakistan Council for Scientific and Industrial Research (PCSIR) Laboratories Complex, University Road Peshawar, KP, Pakistan

Received December 27, 2017

A novel poly(acrylic acid-co-acrylamide)/sawdust composite was synthesized by copolymerization of partially neutralized acrylic acid and acrylamide with sawdust using $\mathrm{N}, \mathrm{N}$-methylenebisacrylamide as a crosslinker and potassium persulfate/sodium sulphite as initiators. The composite was characterized by FTIR, XRD, SEM, EDX and BET techniques. The adsorption of $\mathrm{Cd}(\mathrm{II})$ and $\mathrm{Pb}$ (II) ions on composite in aqueous solution was studied in batch experiments optimizing reaction parameters like initial concentration, contact time, $\mathrm{pH}$ and temperature. The adsorption kinetics followed pseudo second order kinetic model. Adsorption isotherms were applied to the experimental data which fitted well with Langmuir and Freundlich isotherms. The maximum adsorption capacities $\left(\mathrm{q}_{\mathrm{m}}\right)$ (from Langmuir model) of the prepared composite at 25 ${ }^{\circ} \mathrm{C}$, were $28.57 \mathrm{mg} \mathrm{g}^{-1}$ and $32.25 \mathrm{mg} \mathrm{g}^{-1}$ for $\mathrm{Cd}(\mathrm{II})$ and $\mathrm{Pb}(\mathrm{II})$ ions, respectively. Activation energy data $\left(12.148 \mathrm{~kJ} \mathrm{~mol}^{-1}\right.$ and $7.165 \mathrm{~kJ} \mathrm{~mol}^{-1}$ $\mathrm{Cd}(\mathrm{II})$ and $\mathrm{Pb}(\mathrm{II})$, respectively) indicated physiosorption. Results of thermodynamic parameters like $\Delta \mathrm{G}^{\circ}, \Delta \mathrm{H}^{\circ}$ and $\Delta \mathrm{S}^{\circ}$ for both $\mathrm{Cd}(\mathrm{II})$ and

GRAPHICAL ABSTRACT

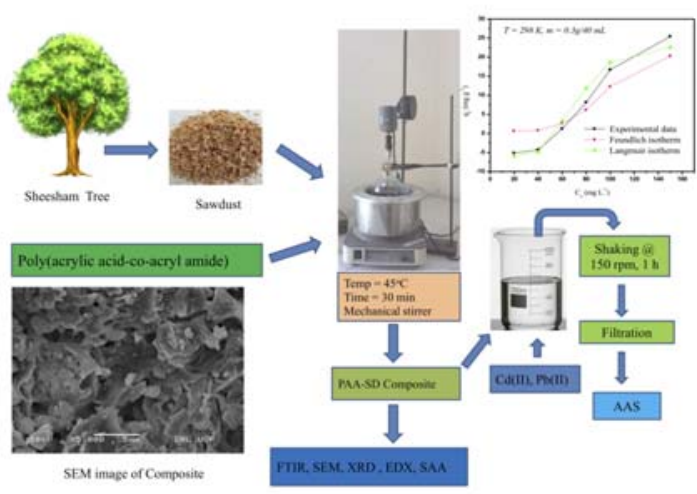
$\mathrm{Pb}(\mathrm{II})$ ions suggested the spontaneity and endothermic nature of the process. The newly synthesized composite attributed to its cost effective and environment friendly nature and ease of synthesis, could be deemed as a potential candidate for the removal of Cd(II) and $\mathrm{Pb}$ (II) ions from waste-water.

\section{INTRODUCTION}

Heavy metal pollution is a serious environmental problem of global concern caused by rapid growth in industrialization. They are generally hazardous, nonbiodegradable and persistent in nature. ${ }^{1}$ They cause serious detrimental effects on biotic as well as abiotic segments of ecosystem including health hazards in human and plants. ${ }^{2}$ These metals include $\mathrm{Pb}, \mathrm{Cd}, \mathrm{Cr}$, As etc. ${ }^{3}$ Metal plating, lead acid batteries, printing, glass and ceramic industries, lead mining, phosphate fertilizers, forest fires, electronics, and automobile emission are the major sources of lead $(\mathrm{Pb})$ pollution. ${ }^{4} \mathrm{~Pb}$ has been reported with problems like brain and kidney dysfunction, miscarriage, under developed fetus, disruption of nervous system and infertility. ${ }^{5}$ Severe exposure to $\mathrm{Pb}$ causes abortion, sterility, neo-natal deaths and stillbirths. ${ }^{6}$ The world health organization (WHO) drinking water standard for $\mathrm{Pb}$ is $0.01 \mathrm{mg} / \mathrm{L}{ }^{7}$ Similar to $\mathrm{Pb}$, cadmium (Cd) is

* Corresponding author: atasafi@hotmail.com 
another highly toxic pollutant released by industries like metallurgical alloying, photography, electroplating, $\mathrm{Cd}$ batteries, pigments, textile print, phosphate fertilizers etc. ${ }^{8}$ Toxicity of $\mathrm{Cd}$ causes cancer, bone lesions, hypertension, lung deficiency and Itai-Itai. ${ }^{9}$ Attributed to its highly toxic nature, WHO has crammed its permissible limit in drinking water to $0.02 \mathrm{mg} \mathrm{L}^{-1} .{ }^{10}$ Due their toxic and detrimental effects on living organisms and environment, removal of $\mathrm{Cd}$ and $\mathrm{Pb}$ from aqueous media has been a major centre of research for scientists.

Many approaches have been adopted for the removal of heavy metal including chemical precipitation, ${ }^{11}$ electrochemical treatment, ${ }^{12}$ chemical oxidation/reduction, ${ }^{13}$ reverse osmosis, ${ }^{14}$ ion exchange, ${ }^{15}$ electrodialysis ${ }^{16}$ and evaporation. ${ }^{17}$ These techniques usually require high maintenance cost and expensive facilities. On the contrary, researchers are always craving a low cost, simplified, effective and environment friendly method as alternative approach. In this regard, adsorption is considered an economical, effective, simple and widely applied method. ${ }^{18}$ Rice husk, ${ }^{19}$ corncorb,${ }^{20}$ tea waste, ${ }^{21}$ bagasse fly ash ${ }^{22}$ sawdust (Pinus halepensis), ${ }^{23}$ meranti tree sawdust, ${ }^{24}$ coconut shells, ${ }^{25}$ apricot stone, ${ }^{26}$ rice husk ash, ${ }^{27}$ walnut sawdust, ${ }^{28}$ olive cake ${ }^{29}$ and pine sawdust (Pinus sylvestris) $^{3}$ have been reported for the removal of $\mathrm{Cd}$ and $\mathrm{Pb}$ from aqueous solutions. To the best of our knowledge, no reports on the application of poly(acrylic acid-co-acrylamide)/sawdust (PAA-SD) composite for the adsorptive removal of $\mathrm{Pb}$ and $\mathrm{Cd}$ has been reported so far.

Thus, this study focuses on the synthesis of PAA-SD composite by the combination of Dalbergia sissoo (sheesham) sawdust (SD) and poly(acrylic acid-co-acrylamide) for adsorptive removal of $\mathrm{Cd}(\mathrm{II})$ and $\mathrm{Pb}(\mathrm{II})$ from aqueous solutions. Reaction parameters were optimized and experimental data were applied to kinetic models for better understanding of the reaction pathway. The pristine sawdust and final composite were characterized by X-ray diffraction (XRD), scanning electron microscopy (SEM), BrunauerEmmett-Teller (BET), energy dispersive X-ray analysis (EDX) and Fourier transformed infra-red (FTIR) spectroscopy.

\section{EXPERIMENTAL}

\section{Materials}

All the reagents were of analytical grade and used without further purification. Monomers acrylic acid (99\%), Potassium persulfate (KPS 98\%) and acrylamide $(98 \%)$ were obtained from DAEJUNG reagents chemicals. KPS and Sodium sulphite (95\%) anhydrous (by Riedel-deHaën) were used as initiator and accelerator, respectively. Sodium hydroxide (99\%) was provided by Merck. Cross-linker N,Nmethylenebisacrylamide (MBA, 98.5\%) was provided by UNI-Chem ${ }^{\circledR}$ chemical reagents. Double distilled water was used throughout the experimental work.

\section{Sawdust}

Dalbergia sissoo SD was obtained from timber shop near Peshawar University, KP, Pakistan. The sample was washed with water to remove surface impurities and dried for $24 \mathrm{~h}$ at ambient temperature. The SD sample was put in quartz tube which was then placed in tubular furnace and heated at $170{ }^{\circ} \mathrm{C}\left( \pm 5^{\circ} \mathrm{C}\right)$ for 45 minutes in nitrogen flow rate of $40 \mathrm{~mL} /$ minute. This activated sample was washed in a soxhlet extractor at $100{ }^{\circ} \mathrm{C}$ with distilled water and dried in oven for five hours at $110{ }^{\circ} \mathrm{C}$. Dried samples were screened from $100 \mu m$ mesh (U.S Standard sieve).

\section{Synthesis}

of poly(acrylic acid-co-acryl amide) copolymer

Cross-linked copolymer of acrylic acid $(3 \mathrm{~mL})$ and acrylamide $(0.2 \mathrm{~g})$ were prepared by solution polymerization method using acrylic acid monomer, acrylamide and N,N-methylenebisacrylamide (MBA, $0.2 \mathrm{~g}$ ). A redox initiating system, consisting of potassium persulfate and sodium sulphite $(0.2 \mathrm{~g}$ each) was used as an initiator. The proposed mechanism for the reaction is provided in Scheme 1 below.

\section{Synthesis of poly(acrylic acid-co-acrylamide)/Sawdust composite (PAA-SD)}

A PAA-SD composite was synthesized by solution polymerization method reported elsewhere. ${ }^{30}$ Acrylic acid $(3 \mathrm{~mL})$ was dissolved in $20 \mathrm{~mL}$ distilled water and solution was partially neutralized with sodium hydroxide solution up to $60 \%$. Sawdust ( $2 \mathrm{~g}$ in $70 \mathrm{~mL}$ distilled water) was dispersed in partially neutralized acrylic acid and acrylamide $(0.2 \mathrm{~g}$ in $10 \mathrm{~mL}$ distilled water) solutions. No sawdust precipitation was observed. The cross-linker, MBA $(0.2 \mathrm{~g}$ dissolved in $10 \mathrm{~mL}$ distilled water) was added to the mixture of clay solution under $\mathrm{N}_{2}$ atmosphere. Mixture was placed in three-necked round bottom flask followed by its heating in water bath at $45^{\circ} \mathrm{C}$ for $15 \mathrm{~min}$ with uniform shaking via mechanical stirrer at $250 \mathrm{rpm}$ till complete dissolution of MBA. Initiators $\left(\mathrm{Na}_{2} \mathrm{SO}_{3}\right.$ and KPS, $0.2 \mathrm{~g}$ of each dissolved in $10 \mathrm{~mL}$ distilled water separately) were added to the flask and stirred for $30 \mathrm{~min}$ to ensure complete consumption of monomers and composite formation. The rubbery gel was removed from the flask and dried at $80{ }^{\circ} \mathrm{C}$ in vacuum oven till solid mass is obtained.

\section{Characterization}

The FTIR spectra of PAA-SD composite were recorded on FTIR, Model 1760x, Perkin-Elmer Infrared Spectrometer. The structure and crystallinity of the composite was identified using XRD Model JDX-3532 (JEOL, Japan) operating with $\mathrm{Cu}-\mathrm{K} \alpha$ radiations $\left(\lambda=1.5418^{\circ} \mathrm{A}\right)$ at an angle $(2 \theta)$ ranging from 0 to $80^{\circ}$, an accelerating voltage of $20-40 \mathrm{kV}$ and an applied current of 2.5-30 mA. Elemental analysis was conducted using EDX analyzer (INCA-200/Oxford instruments, U.K) fixed with SEM (JSM 5910, JEOL Japan). The morphology of PAA-SD composite was examined using SEM (Model JSM5910 JEOL Japan). Surface area of the composite was determined by $\mathrm{N}_{2}$ adsorption of method at $77 \mathrm{~K}$ applying BET technique surface area analyzer (NOVA 2200e, Quantachrome, USA). 


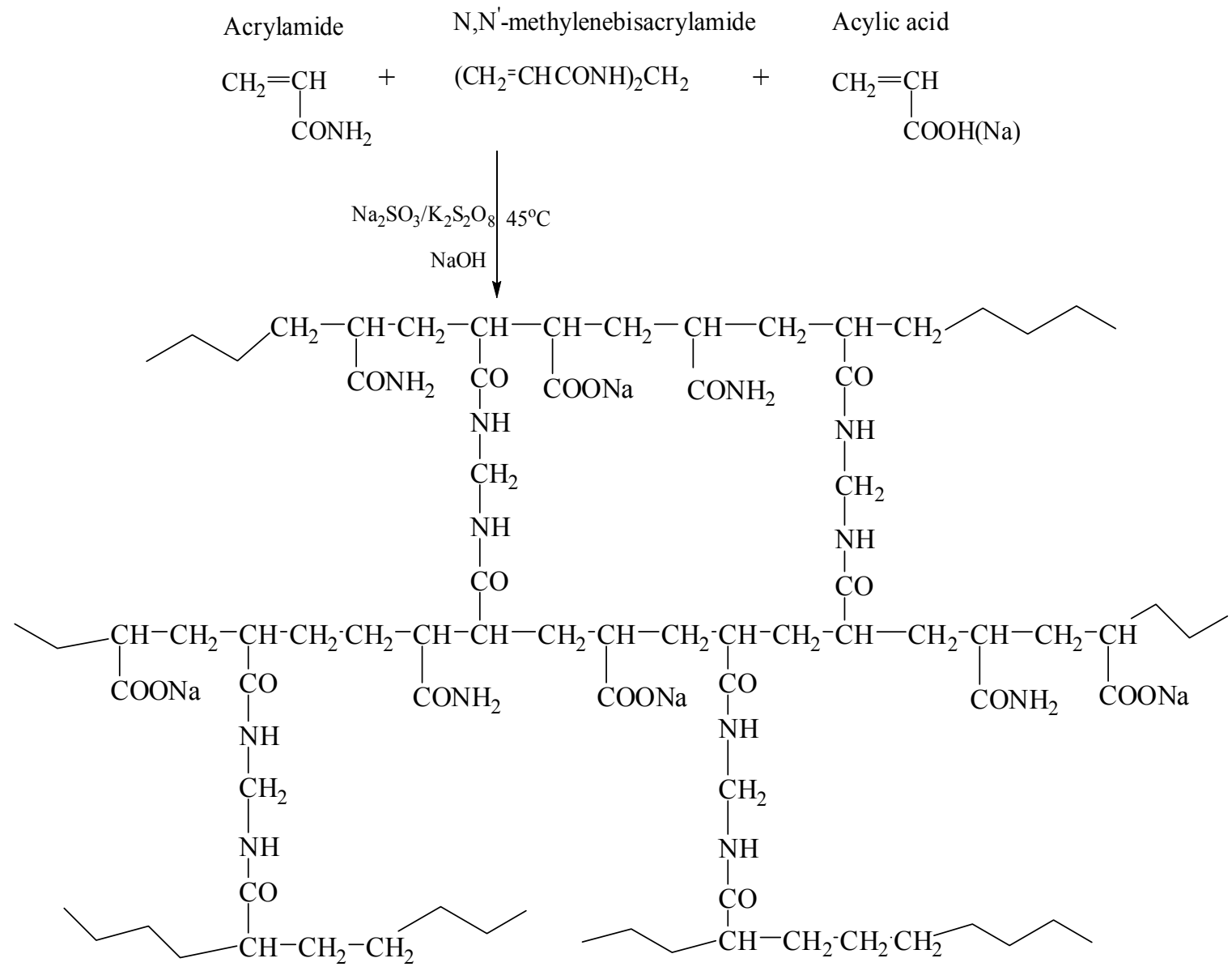

Cross-linked coplymer of acrylic acid and acrylamide

Scheme 1 - Synthesis route and structure of Poly(acrylic acid-co-acrylamide) copolymer.

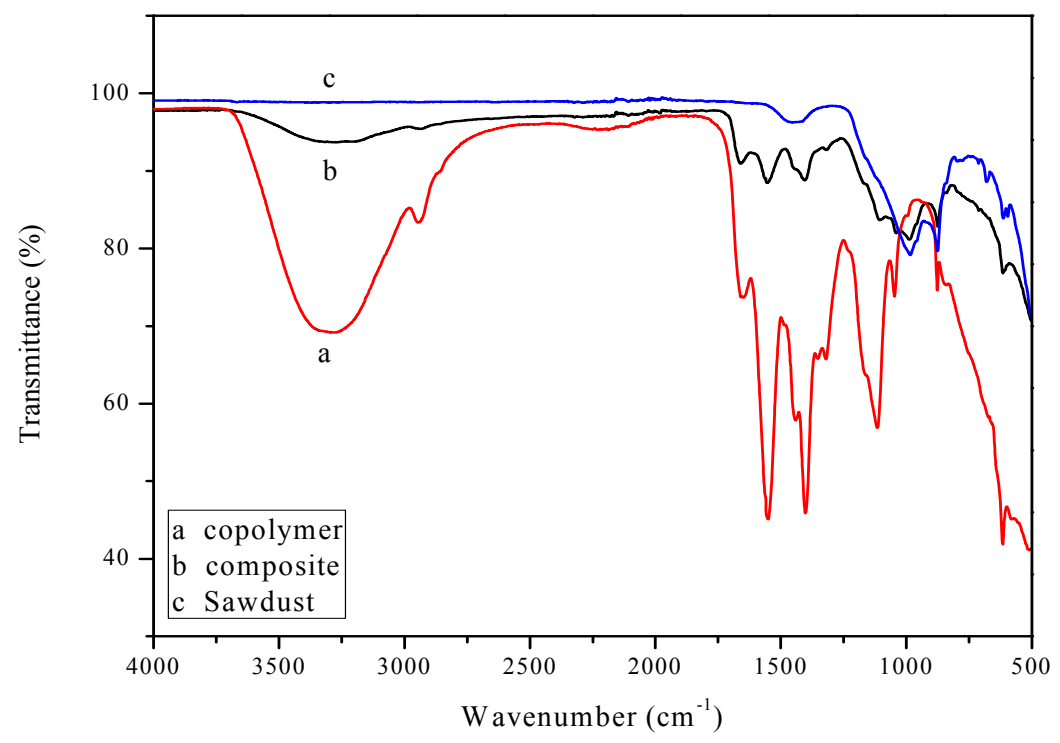

Fig. 1 - FTIR spectra of sawdust, copolymer and composite.

\section{Adsorption experiments}

Separate aqueous solutions of $\mathrm{Cd}(\mathrm{II})$ and $\mathrm{Pb}(\mathrm{II})$ ions (100 ppm each) were used to conduct adsorption experiments. In a typical run, $40 \mathrm{~mL}$ of adsorbate and $0.3 \mathrm{~g}$ of PAA-SD were taken in a conical flask and shaken in water shaker at $150 \mathrm{rpm}$ and $25{ }^{\circ} \mathrm{C}$ for $3 \mathrm{~h}$. After shaking, solutions were filtered through Whatman $125 \mathrm{~mm}$ filter paper and analyzed for $\mathrm{Cd}(\mathrm{II})$ and $\mathrm{Pb}(\mathrm{II})$ ions concentration using Atomic adsorption spectrometer (AAS) by Eq. (1). 


$$
q=\frac{\left(C_{0}-C_{e}\right)}{m} \times V
$$

where $\mathrm{q}$ is the amount of metal ions adsorbed onto the composite $\left(\mathrm{mg} \mathrm{g}^{-1}\right), \mathrm{C}_{\mathrm{o}}$ and $\mathrm{C}_{\mathrm{e}}$ are the concentration of metal ions in the initial solutions and at equilibrium, respectively $\left(\mathrm{mg} \mathrm{mL}^{-1}\right), \mathrm{V}$ is the volume of the aqueous phase $(\mathrm{mL})$, and $\mathrm{m}$ is the mass of PAA-SD composite $(\mathrm{g})$.

\section{RESULTS AND DISCUSSION \\ 1. FTIR spectrum of sawdust, copolymer and PAA-SD composite}

FTIR spectrum of Dalbergia sissoo SD in Fig. 1 shwon by (c) suggests its complex chemical nature with a variety of functional groups. The peaks at $1449,1283,989,870,811,669,621 \mathrm{~cm}^{-1}$ represent symmetric bending of $\mathrm{CH}_{3}$, surface hydroxyl, phenolic group stretching, $\mathrm{CO}$ phenolic group stretching, cellulose, $\mathrm{CH}$ bending, $\mathrm{NH}$ bond and alkyl halide groups of $\mathrm{CBr}$ stretching vibration, respectively. ${ }^{31}$ Similarly, FTIR spectrum of poly(acrylic acid-co-acrylamide) copolymer in Fig. 1 shown by (a) shows peaks at 3315, 2960, 2586, 1627 and $1408 \mathrm{~cm}^{-1}$ ascribed to $\mathrm{NH}$ stretching vibration of acrylamide unit, acrylate unit of $\mathrm{CH}$ stretching, $\mathrm{OH}$ stretching, stretching of $\mathrm{C}=\mathrm{O}$ in acrylate unit and $\mathrm{CN}$ group, respectively. ${ }^{32}$ These results confirmed the successful reaction between acrylic acid and acrylamide. ${ }^{32}$

The FTIR spectrum of PAA-SD composite is given in Fig. 1 shown by (b). The 3273, $2948 \mathrm{~cm}^{-1}$ peaks indicate stretching vibration of $\mathrm{OH}$ band and stretching vibration of $\mathrm{CH}$, respectively.
Stretching vibration of $\mathrm{C}=\mathrm{O}$ carboxylic groups are shown by $1760 \mathrm{~cm}^{-1}$ and $1260 \mathrm{~cm}^{-1}$ while $1558 \mathrm{~cm}^{-1}$ is related to $\mathrm{C}=\mathrm{O}$ bond. Peak at $1395 \mathrm{~cm}^{-1}$ is due to $\mathrm{OH}$ bending and $1125 \mathrm{~cm}^{-1}$ shows $\mathrm{CO}$ stretching vibration of acrylic ester groups. The peaks at round 896,827 and $611 \mathrm{~cm}^{-1}$ are due to $\mathrm{C}-\mathrm{H}$ bending. In the spectra of composite, compared with sawdust and copolymer, some peaks changed in intensity and new peaks appeared which gives the confirmation of reaction between sawdust and copolymer chain. ${ }^{33-35}$

\section{XRD analysis}

$\mathrm{XRD}$ analysis is a useful tool for intercalation in sawdust investigations. Fig. 2 shows the XRD patterns of SD, copolymer and their composite, respectively. It was observed that PAA-SD composite diffraction peaks were the same as in raw $\mathrm{SD}$ at $10.900^{\circ}$ is the peak, indicates that the poly(AAc-co-AAm) do not penetrate in the interlayer space efficiently and only covered the surface of SD. It may be due to the large molecular structure of poly(AAc-co-AAm). Similar results are obtained by Huang R et al. when HACC used for medication of bentonite, surface of bentonite is covered by the HACC. Moreover, a clear crystallization $32.350^{\circ}$ peak is seen in poly(AAc-coAAm). However, this peak disappeared in PAA-SD composite. Intensity of $10.900^{\circ}$ diffraction peak in $\mathrm{SD}$ is very weak as compared to composite and suggesting high degree of interaction between poly(AAc-co-AAm) with SD resulting in the successful formation of the composite. ${ }^{36,37}$

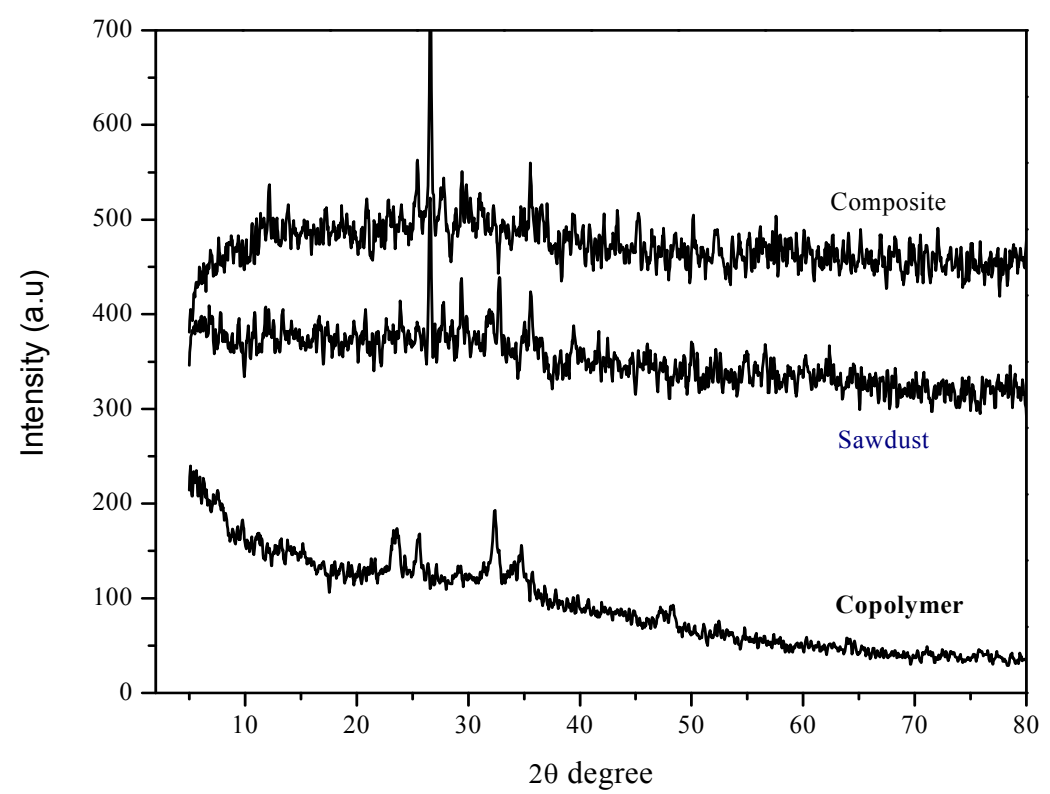

Fig. 2 - XRD spectra of (a) copolymer (b) sawdust and (c) composite. 


\section{SEM analysis}

SEM has been ubiquitously used for characterizing the surface morphology, particle shape, adequate size of pores and porosity of adsorbents. Fig. 3 (a), (b) and (c) show the SEM images of sawdust, copolymer and PAA-SD composite, respectively. The image of sawdust is dark field with rough surface. The surface is porous though are not scattered unevenly in the whole matrix. Due to inorganic elements the surface, flakes as confirmed by the EDX analysis. ${ }^{38}$ Fig. 3 (c) shows the SEM image of composite which suggests a number of pores in different shapes and size compared with sawdust and copolymer. It is suggested that these pores are the region of adsorption for toxic metals from contaminated water. Roughness of surface indicates the high surface area.

\section{Surface area analysis}

In any adsorption or surface interaction based process, surface area plays an important role and greater surface provide higher chances of adsorbent-heavy metal ion interaction resulting in higher adsorption capacity and vice versa. ${ }^{39}$ The BET surface area of the composite was determined by $\mathrm{N}_{2}$ adsorption method ${ }^{40}$ and was found to be $32.316 \mathrm{~m}^{2} / \mathrm{g}$.

\section{EDX analysis}

EDX study of sawdust, copolymer and PAASD composite was conducted to test their elemental composition. The atomic $\%$ and weight $\%$ of different elements were determined and shown in Fig. 4(a), (b) and (c), which indicated that composite has the highest percentage of oxygen $(40.50 \%)$ followed by carbon $(39.94 \%)$ and nitrogen $(5.24 \%)$.

\section{Adsorption studies}

\subsection{Effect of initial concentration}

Effect of initial concentration of $\mathrm{Cd}(\mathrm{II})$ ions on composite is shown in Fig. 5. With increase in initial concentration from 20-250 ppm, using $0.3 \mathrm{~g} / 40 \mathrm{~mL}$ adsorbent dose, the adsorption efficiency increases. At higher initial concentration, adsorption is fast owing to high availability of active sites on surface of composite then increases slowly and attains a constant value. Further increase in concentration has no prominent effect on adsorption owing to the saturation of active sites on composite with heavy metals ions. Maximum amount of $\mathrm{Cd}(\mathrm{II})$ ions is adsorbed at a concentration of $200 \mathrm{mg} \mathrm{L}^{-1}$. Similar trend in adsorption results was obtained for $\mathrm{Pb}$ (II) ions on PAA-SD composite.

\subsection{Effect of contact time}

The effect of contact time on the adsorption of $\mathrm{Cd}(\mathrm{II})$ and $\mathrm{Pb}$ (II) over composite was studied at an initial metal ion concentration of $200 \mathrm{ppm}, 0.3 \mathrm{~g}$ adsorbent and $40 \mathrm{~mL}$ of ion solution. From Fig. 6 it is clear that adsorption rate is very fast initially (first $20 \mathrm{~min}$ ) and keeps on increasing slowly till $60 \mathrm{~min}$ before attaining equilibrium. The initial high adsorption rate is due to the abundance of free adsorption sites, which become saturated with the passage of time and results in decreased adsorption rate. From Fig. 6, a contact time of $60 \mathrm{~min}$ was chosen for onward experiments.

\subsection{Effect of $\mathrm{pH}$}

The effect of $\mathrm{pH}$ on the adsorption of $\mathrm{Cd}$ (II) and $\mathrm{Pb}(\mathrm{II})$ on PAA-SD composite was studied and the results are compiled in Fig. 7. The adsorption of $\mathrm{Cd}(\mathrm{II})$ increases with increasing $\mathrm{pH}$ and maximum adsorption was observed at $\mathrm{pH}$ 5. With further increase in $\mathrm{pH}$, adsorption decreases. A similar trend for the adsorption of $\mathrm{Pb}$ (II) was also observed by varying $\mathrm{pH}$ from 2 to 9 . The maximum adsorption was observed at $\mathrm{pH} 6$ but adsorption decreases with further increase of $\mathrm{pH}$. At lower $\mathrm{pH}$, lower adsorption was due to competitive adsorption between $\mathrm{H}^{+}$ions and metal ions towards active sites. Moreover, the positive charges is increased on the surface of composite which hinder further adsorption of positively charged metal ions due to electrostatic repulsion. Thus $\mathrm{pH} 6$ was chosen as optimum $\mathrm{pH}$ for both the metal ions, which consistent with some reported literature for $\mathrm{Cd}(\mathrm{II})$ and $\mathrm{Pb}(\mathrm{II})$ adsorption. ${ }^{41}$

\subsection{Effect of temperature}

Temperature is an important factor that greatly affects the adsorption process. Effect of temperature on the adsorption of the two metals was studied in a range of $25-45{ }^{\circ} \mathrm{C}$ as shown in Fig. 8. The rate of adosrption of $\mathrm{Cd}(\mathrm{II})$ and $\mathrm{Pb}(\mathrm{II})$ increased by increasing temperature from 25 to $45{ }^{\circ} \mathrm{C}$, indicating the endothermic nature of adsorption process. This may be due to fast molecular movements and activation of $\mathrm{Cd}(\mathrm{II})$ and $\mathrm{Pb}$ (II) towads the active sites of adsorbent. 


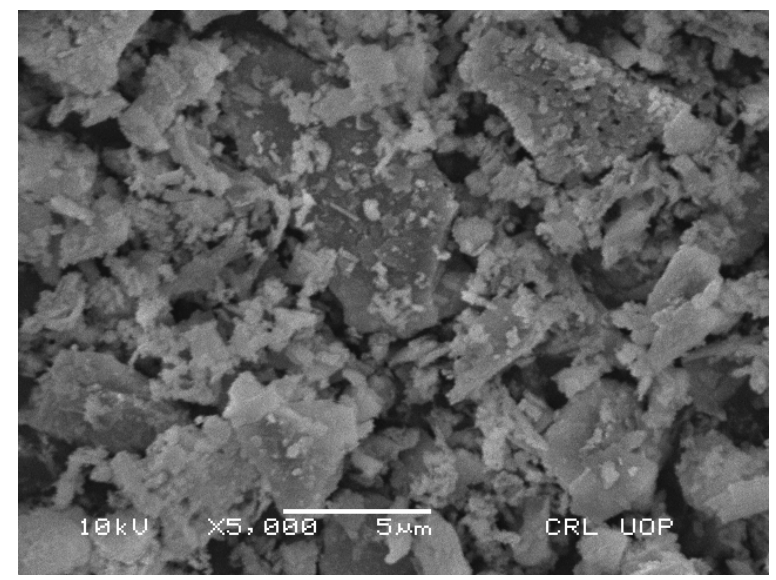

Fig. 3(a) - SEM image of sawdust.

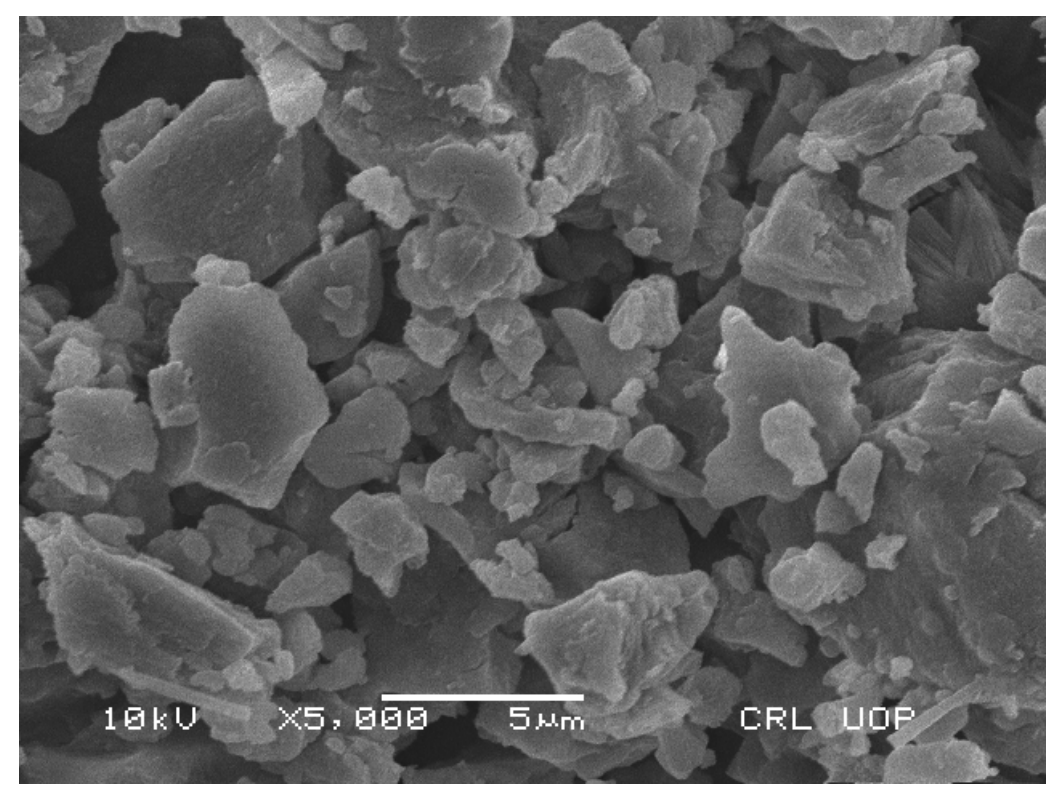

Fig. 3(b) - SEM image of copolymer.

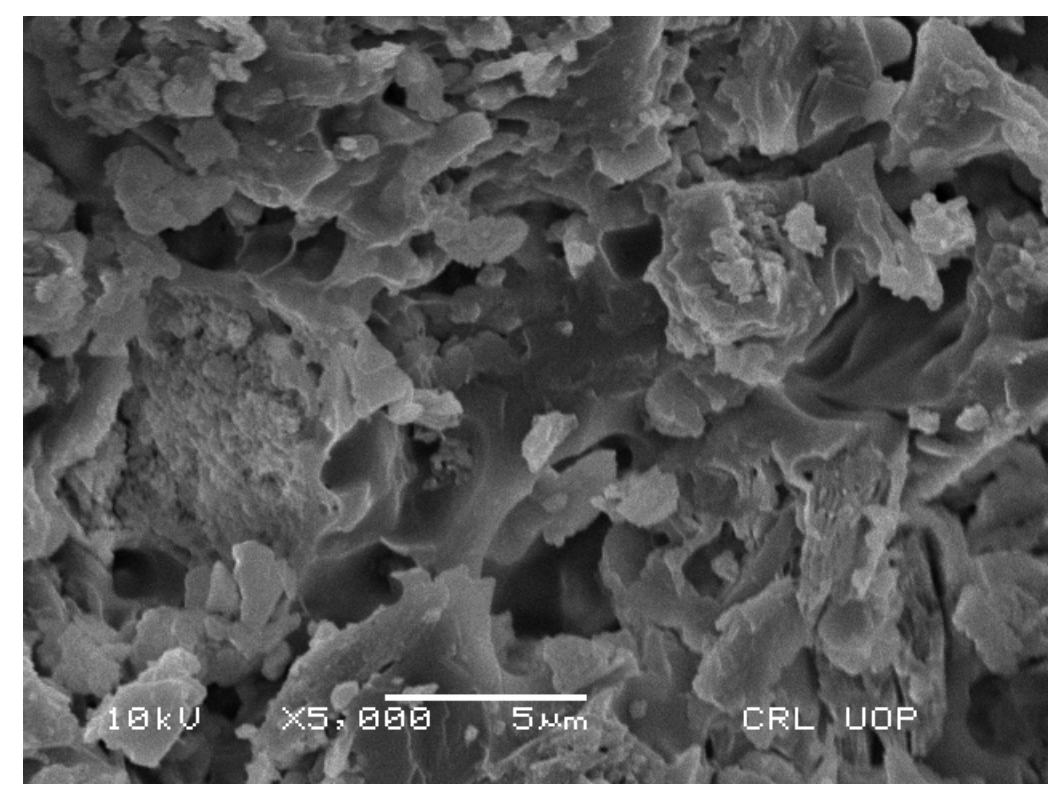

Fig. 3(c) - SEM image of PAA-SD composite. 


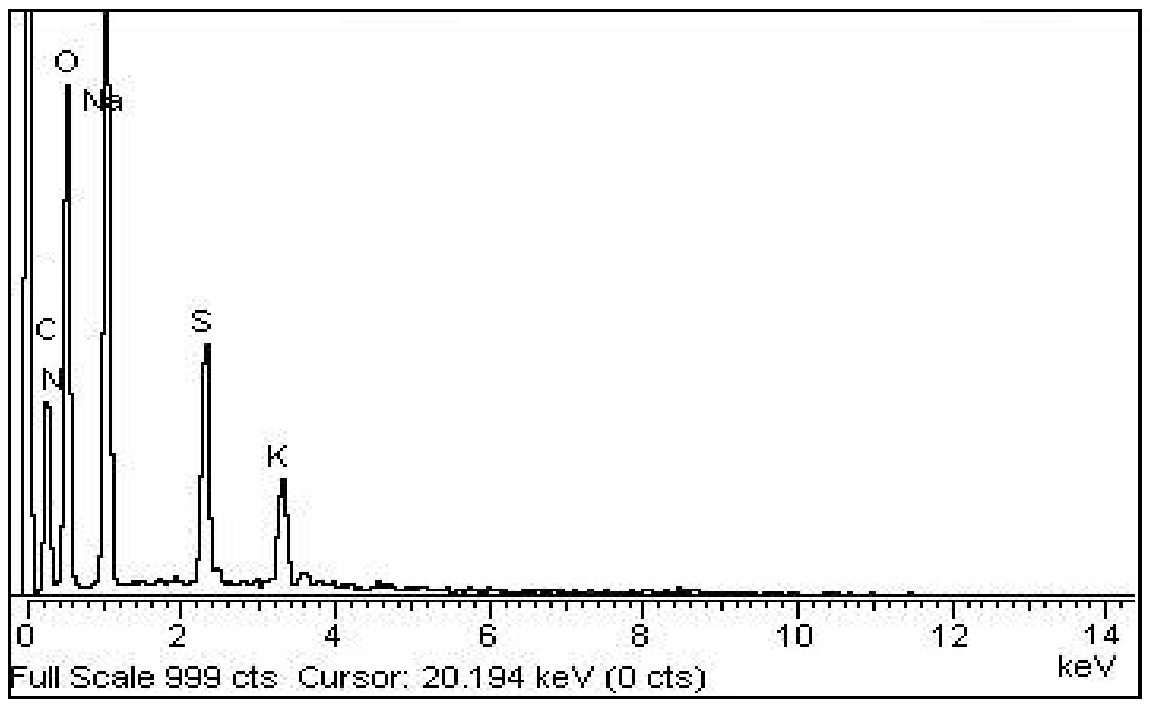

Fig. 4(a) - EDX spectrum of PAA copolymer.

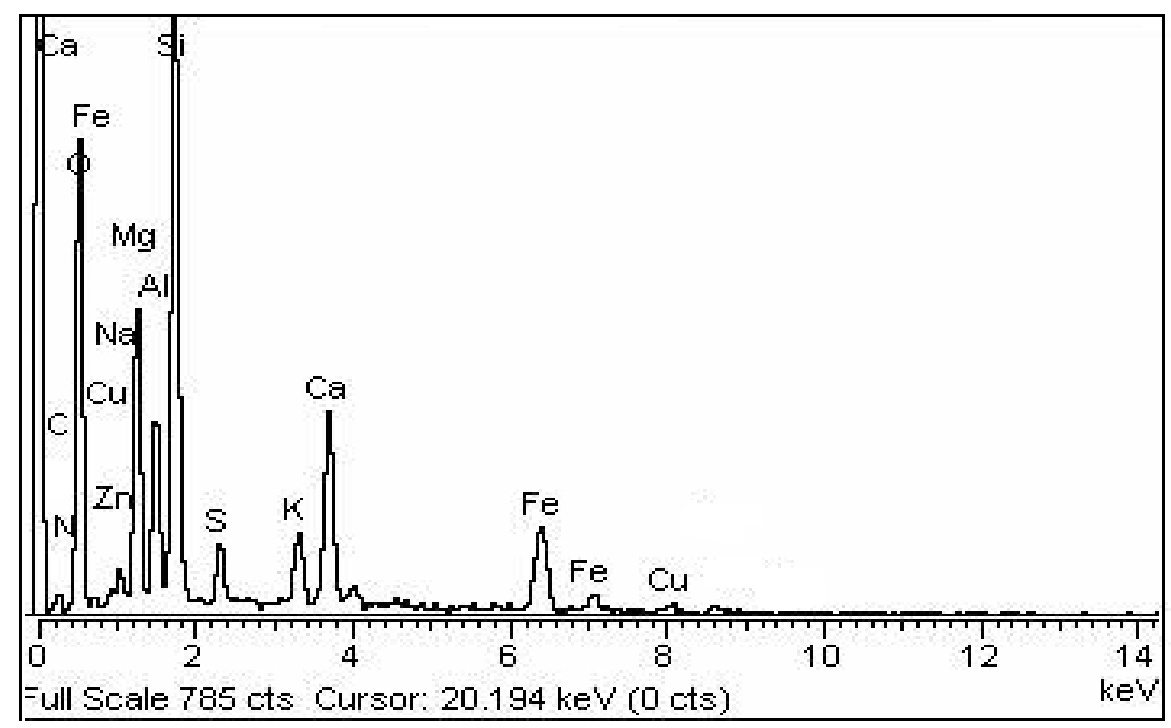

Fig. 4(b) - EDX spectrum of Dalbergia sissoo SD.

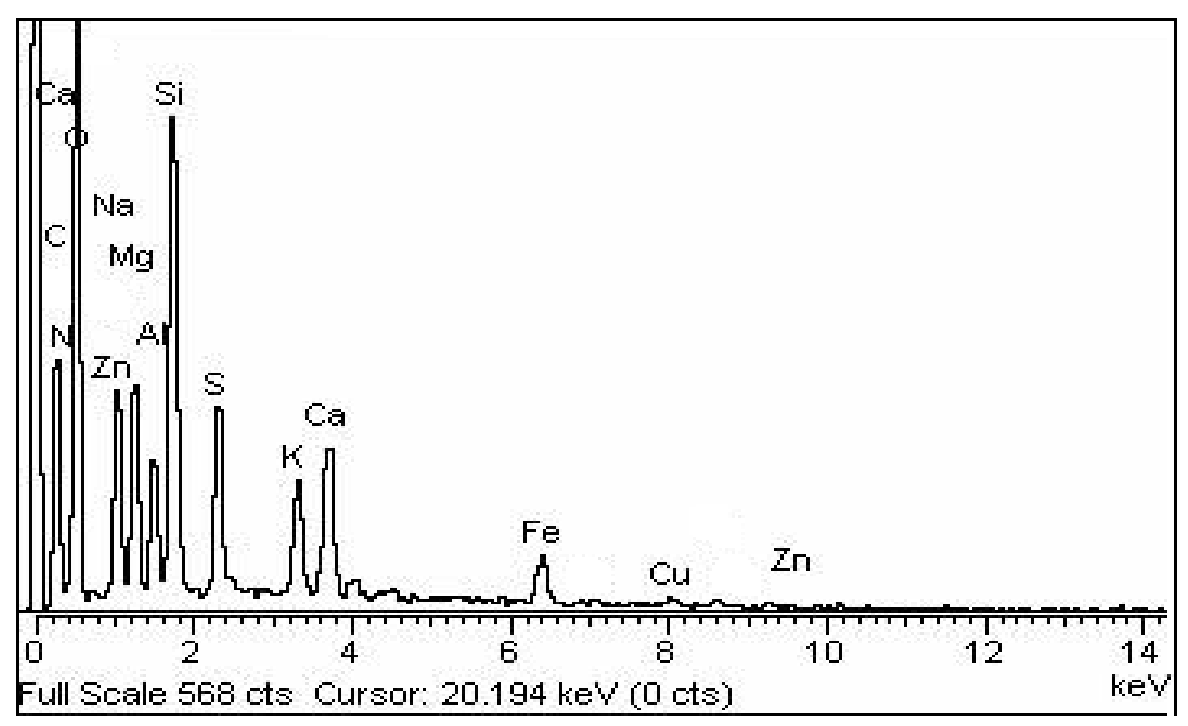

Fig. 4(c) - EDX spectrum of PAA-SD composite. 


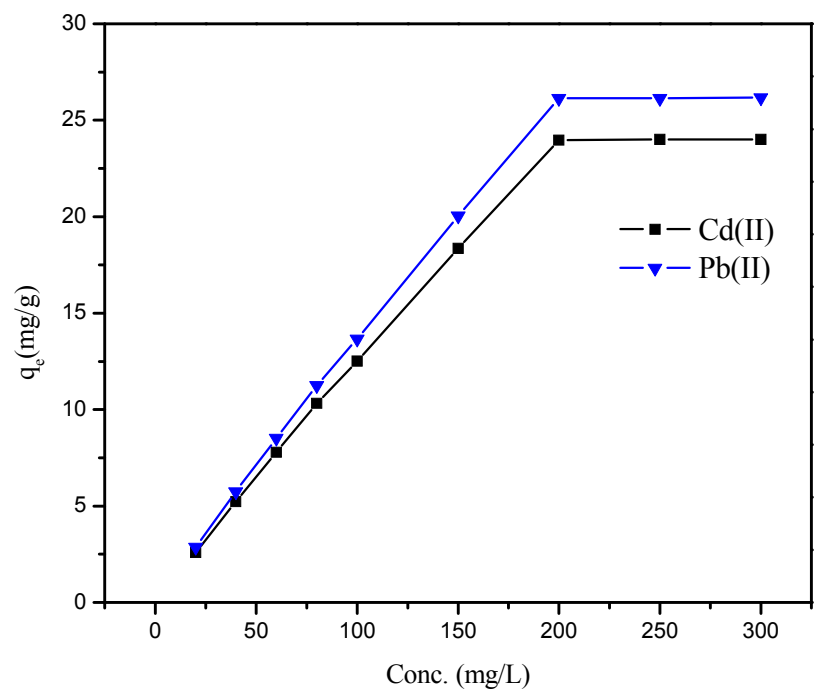

Fig. 5 - Effect of initial metal ion concentration on PAA-SD composite at $25^{\circ} \mathrm{C}, 0.3 \mathrm{~g}$ of adsorbent and $40 \mathrm{~mL}$ of sample solution.

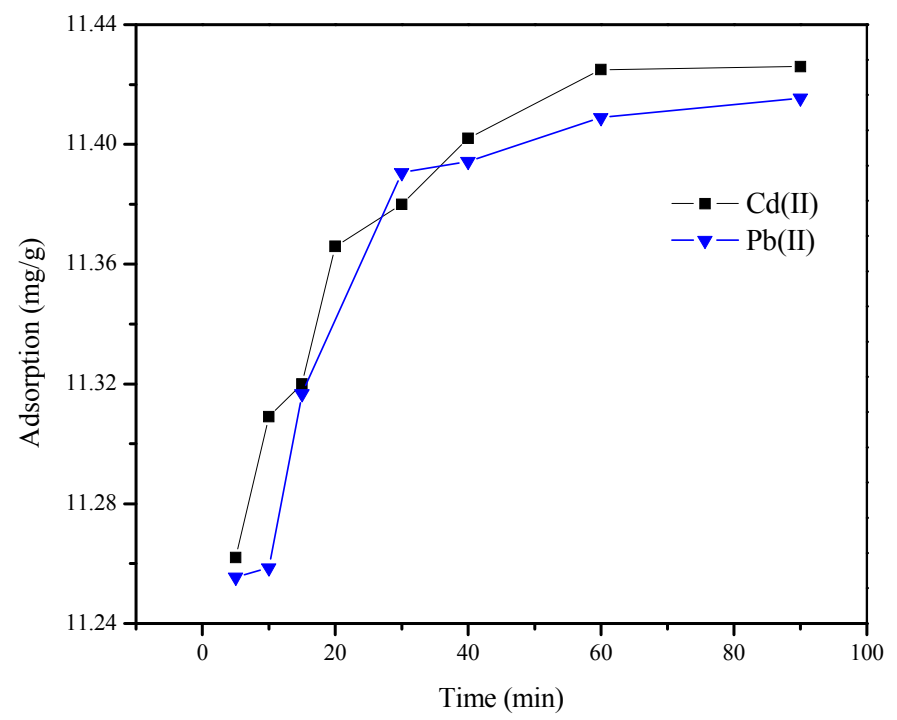

Fig. 6 - Effect of contact time on the adsorption of $\mathrm{Cd}(\mathrm{II})$

and $\mathrm{Pb}(\mathrm{II})$ ions at $25^{\circ} \mathrm{C}, 0.3 \mathrm{~g}$ of adsorbent and $40 \mathrm{~mL}$ of $200 \mathrm{ppm}$ sample solution.

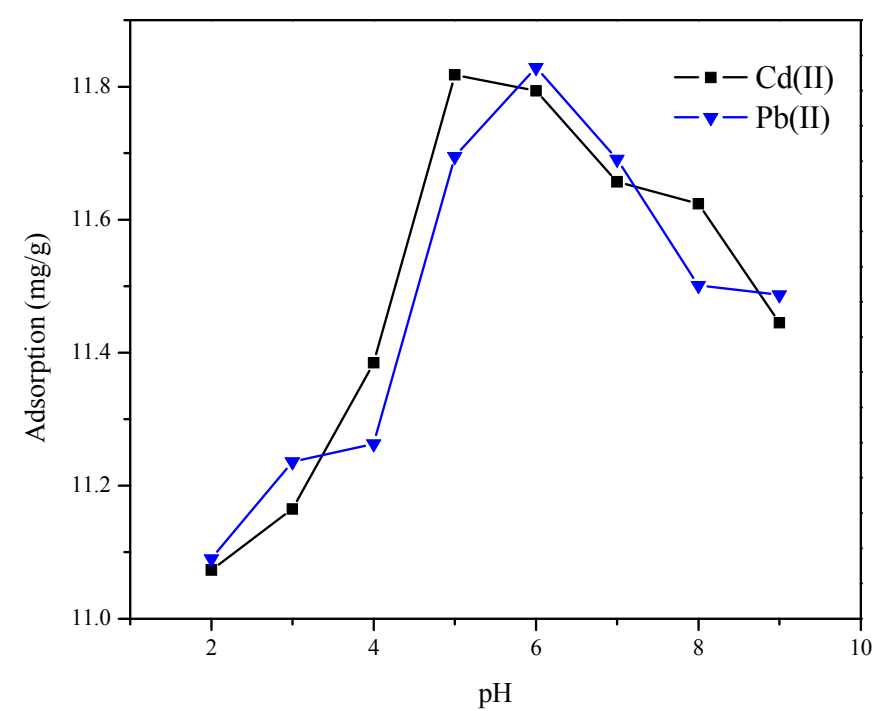

Fig. 7 - Effect of $\mathrm{pH}$ on adsorption of $\mathrm{Cd}(\mathrm{II})$ and $\mathrm{Pb}(\mathrm{II})$ ions on PAA-SD composite at $25{ }^{\circ} \mathrm{C}, 0.3 \mathrm{~g}$ of adsorbent, $60 \mathrm{~min}$ time, and $40 \mathrm{~mL}$ of $200 \mathrm{ppm}$ sample solution. 


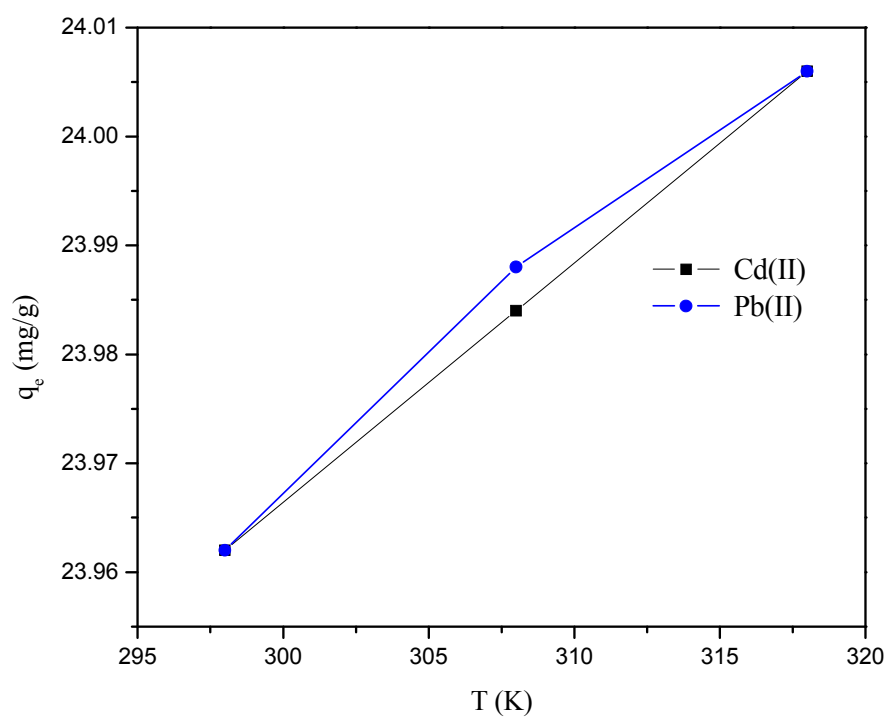

Fig. 8 - Effect of temperature on adsorption of $\mathrm{Cd}(\mathrm{II})$ and $\mathrm{Pb}(\mathrm{II})$ ions on PAA-SD composite.

\section{Adsorption kinetics}

The adsorption kinetics is an important parameter with respect which can better describe the nature and path of adsorption process using some well-established mathematical equations to determine adsorption rate. In order to study the adsorption process of $\mathrm{Cd}$ (II) and $\mathrm{Pb}$ (II) ions on composite, pseudo first order and pseudo second order models were applied to experimental data.

\section{a. Pseudo first order}

The pseudo first order shown by Eq. (2) given by Lagergren was used to analyze the experimental data. $^{42}$

$$
\log \left(q_{e}-q_{t}\right)=-\frac{k_{1} t}{2.303}+\log q_{e}
$$

where $\mathrm{q}_{\mathrm{e}}\left(\mathrm{mg} \mathrm{g}^{-1}\right)$ is the amount of metal ion adsorbed at equilibrium, $\mathrm{q}_{\mathrm{t}}\left(\mathrm{mg} \mathrm{g}^{-1}\right)$ is the amount of metal ions adsorbed at time $\mathrm{t}$ and $\mathrm{k}_{1}\left(\mathrm{~min}^{-1}\right)$ is the rate constant. The values of $\mathrm{k}_{1}$ and $\mathrm{q}_{\mathrm{e}}$ were calculated from the slope and intercept of straight line plot of $\log \left(\mathrm{q}_{\mathrm{e}}-\mathrm{q}_{\mathrm{t}}\right)$ versus $\mathrm{t}$ (Fig. 9), respectively and were reported in Table 1. Greater discrepancies were observed between $q_{e}$ values determined from the model and experimental. This suggested that the current adsorption process of $\mathrm{Cd}(\mathrm{II})$ and $\mathrm{Pb}(\mathrm{II})$ did not follow pseudo first order kinetics.

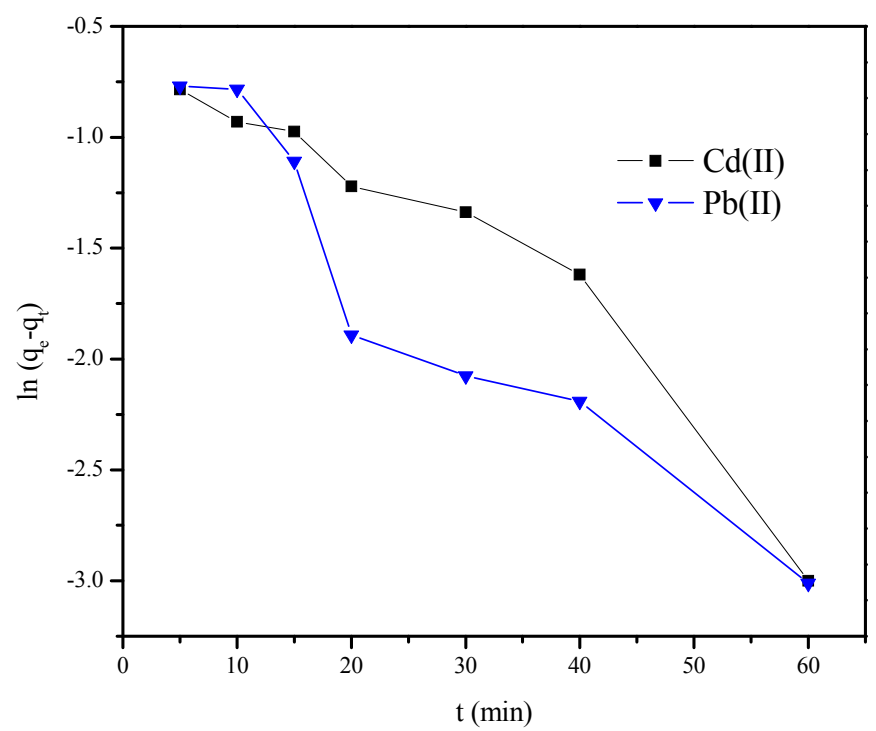

Fig. 9 - Plot of pseudo first order kinetics for $\mathrm{Cd}(\mathrm{II})$ and $\mathrm{Pb}(\mathrm{II})$ ions adsorption on PAA-SD composite. 


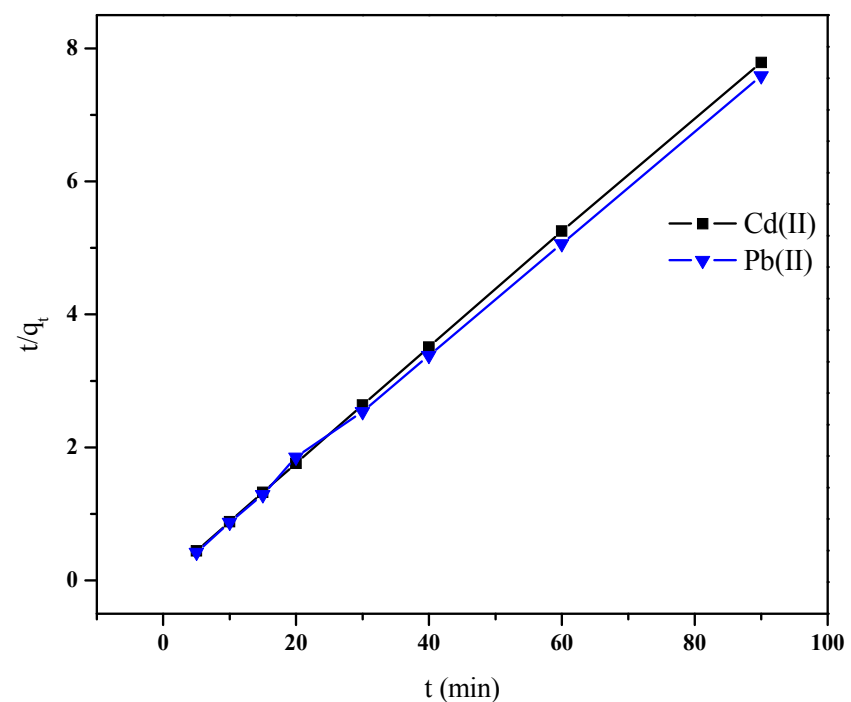

Fig. 10 - Plot of pseudo second order kinetics for $\mathrm{Cd}(\mathrm{II})$ and $\mathrm{Pb}(\mathrm{II})$ ions adsorption on PAA-SD composite.

\section{b. Pseudo second order}

Pseudo second order kinetic model suggested by McKay and Ho was also used to explore the metal ions adsorption data using equation (3). ${ }^{43}$

$$
\frac{t}{q_{t}}=\frac{1}{k_{2} q_{e}^{2}}+\frac{1}{q_{e}} t
$$

where $\mathrm{k}_{2}\left(\mathrm{~g} \mathrm{mg}^{-1} \mathrm{~min}^{-1}\right)$ is the rate constant of pseudo second order kinetics and $\mathrm{q}_{\mathrm{e}}$ and $\mathrm{q}_{\mathrm{t}}$ are the same as those mentioned in Eq. (1). The values of $\mathrm{k}_{2}$ and $\mathrm{q}_{\mathrm{e}}$ were calculated from the slope and intercept of straight line plot of $t / q_{t}$ versus $t$ (Fig. 10), respectively and reported in Table 1. The regression coefficient $\left(\mathrm{R}^{2}\right)$ values for $\mathrm{Cd}(\mathrm{II})$ and $\mathrm{Pb}$ (II) were 1.0 and 0.999 , which showed the well fitting of experimental data with pseudo second order kinetics. Moreover, the calculated values of $\mathrm{q}_{\mathrm{e}}$ agree significantly with the experimental $\mathrm{q}_{\mathrm{e}}$ values suggest that the process followed pseudo second order kinetics.

\section{Adsorption isotherms}

Adsorption isotherms are very important to design the nature of adsorption process. In the current experimental set up, two well-known isothermal models i.e. Freundlich and Langmuir isotherms were applied to experimental data. ${ }^{44}$

\section{a. Langmuir isotherm}

The Langmuir isotherm suggests that adsorption of metal ions from aqueous solutions occurs on homogenous surface by monolayer coverage with interaction among the adsorbed molecules. The linear form of Langmuir model is given by Eq. (4) ${ }^{45}$ as:

$$
\frac{C_{e}}{q_{e}}=\frac{1}{K_{L} q_{m}}+\frac{1}{q_{m}} \times C_{e}
$$

where $C_{e}$ is the equilibrium concentration of metal ions $\left(\mathrm{mg} \mathrm{L}^{-1}\right), \mathrm{q}_{\mathrm{e}}$ is the amount $\left(\mathrm{mg} \mathrm{g}^{-1}\right)$ of metal ions adsorbed, $\mathrm{q}_{\mathrm{m}}$ and $\mathrm{K}_{\mathrm{L}}$ are Langmuir constants which indicate the adsorption capacity $\left(\mathrm{mg} \mathrm{g}^{-1}\right)$ and energy of adsorption $\left(\mathrm{L} \mathrm{mg}^{-1}\right)$, respectively. The plots of Langmuir isotherms for $\mathrm{Cd}(\mathrm{II})$ and $\mathrm{Pb}(\mathrm{II})$ ions are given in Fig. 11. The value of $\mathrm{q}_{\mathrm{m}}$ and $\mathrm{K}_{\mathrm{L}}$ were calculated from the slope and intercept of linear plot of $\mathrm{C}_{\mathrm{e}} / \mathrm{q}_{\mathrm{e}} \mathrm{vs} \mathrm{C}_{\mathrm{e}}$ and represented in Table 2, which suggested an increase in their values with increasing temperature. The maximum adsorption capacities for $\mathrm{Cd}(\mathrm{II})$ and $\mathrm{Pb}$ (II) ions over PAA-SD composite at $25{ }^{\circ} \mathrm{C}$ were $28.571 \mathrm{mgg}^{-1}$ and $32.25 \mathrm{mgg}^{-1}$ respectively.

Weber and Chackravorti 1974, expressed the Langmuir isotherm in terms of a dimensionless constant called equilibrium parameter or separation factor $\left(\mathrm{R}_{\mathrm{L}}\right)$, which is defined by Eq. $(5)^{46}$.

$$
R_{L}=\frac{1}{1+b C_{i}}
$$

where $\mathrm{K}_{\mathrm{L}}$ is the Langmuir constant and $\mathrm{C}_{\mathrm{i}}$ is the initial concentration of metal ion. Literature revealed that if $R_{L}$ value is less than 1 and greater than zero $\left(0<\mathrm{R}_{\mathrm{L}}<1\right)$, adsorption is favorable while if $1<\mathrm{R}_{\mathrm{L}}$ adsorption is unfavorable. If $\mathrm{R}_{\mathrm{L}}$ value is equal to zero and 1 suggests the irreversible and reversible nature of the adsorption process respectively. ${ }^{47}$ The values of $\mathrm{R}_{\mathrm{L}}$ for adsorption of $\mathrm{Cd}(\mathrm{II})$ at 25,35 and $45{ }^{\circ} \mathrm{C}$ were 
found to be $0.217,0.183$ and 0.147 , respectively while for $\mathrm{Pb}(\mathrm{II})$ under similar conditions were $0.208,0.196$ and 0.190 , respectively. These results suggested the highly favorable nature of the selected metals ions over PAA-SD composite under the specified experimental conditions.

\section{a. Freundlich isotherm}

Freundlich isotherm is an empirical equation that describes the adsorption on heterogeneous adsorbents with interaction among adsorbed molecules. Freundlich adsorption isotherm can be defined by Eq. (6) ${ }^{48}$ in linear form:

$$
\ln q_{e}=\ln K_{F}+\frac{1}{n} \ln C_{e}
$$

where $\mathrm{K}_{\mathrm{F}}\left(\mathrm{L} \mathrm{g}^{-1}\right)$ and $1 / \mathrm{n}$ are Freundlich constants, indicating the adsorption capacity and adsorption intensity, respectively. The plots of Freundlich isotherms for $\mathrm{Cd}(\mathrm{II})$ and $\mathrm{Pb}(\mathrm{II})$ are given in Fig. 12 . Both $1 / \mathrm{n}$ and $\mathrm{K}_{\mathrm{F}}$ were calculated from the slope and intercept of plot of $\ln \mathrm{q}_{e}$ vs $\ln \mathrm{C}_{\mathrm{e}}$ and represented in Table 2. Since the values of $1 / \mathrm{n}$ is lower than 1 showing favorable adsorption scenario. It was found that the adsorption of metal ions on PAA-SD composite fit well with
Freundlich isotherm $\left(\mathrm{R}^{2}=0.956,0.971\right)$ as compared to the Langmuir isotherm $\left(\mathrm{R}^{2}=0.952\right.$, 0.922 ) under identical experimental concentration. Using least square method, the isotherm data were calculated and the concerned correlation coefficients are given in Table 2. Reaction parameters were optimized and experimental data were evaluated using kinetic models for better understanding of the reaction pathway.

\section{Activity comparison of PAA-SD composite with reported adsorbents}

Table 3 shows the comparison of maximum adsorption capacities of $\mathrm{Cd}(\mathrm{II})$ and $\mathrm{Pb}$ (II) ions on PAA-SD composite with earlier reported adsorbents. The results indicate that the maximum adsorption capacities of metal ions on PAA-SD composite was higher than those reported in literature. These superior data in terms of adsorption capacity and cost effective nature of PAA-SD composite suggest that this novel composite has high potential for practical application on industrial level involving wastewater treatment.

Kinetic constants for $\mathrm{Cd}(\mathrm{II})$ and $\mathrm{Pb}(\mathrm{II})$ ions adsorption on PAA-SD composite

\begin{tabular}{|c|c|c|c|c|c|c|}
\hline \multirow[t]{2}{*}{ Metal ion } & \multicolumn{3}{|c|}{ Pseudo first order parameters } & \multicolumn{3}{|c|}{ Pseudo second order parameters } \\
\hline & $\mathrm{q}_{\mathrm{e}}\left(\mathrm{mg} \mathrm{g}^{-1}\right)$ & $\overline{K_{1}\left(\min ^{-1}\right)}$ & $\mathbf{R}^{2}$ & $q_{e}\left(m g ~ g ~ g^{-1}\right)$ & $\mathrm{K}_{2}\left(\mathrm{~g} \mathrm{mg}^{-1} \min ^{-1}\right)$ & $\mathbf{R}^{2}$ \\
\hline $\mathrm{Cd}(\mathrm{II})$ & 2.779 & 0.0852 & 0.915 & 11.494 & 1.081 & 1.0 \\
\hline $\mathrm{Pb}(\mathrm{II})$ & 1.183 & 0.0575 & 0.918 & 11.363 & 0.0944 & 0.999 \\
\hline
\end{tabular}

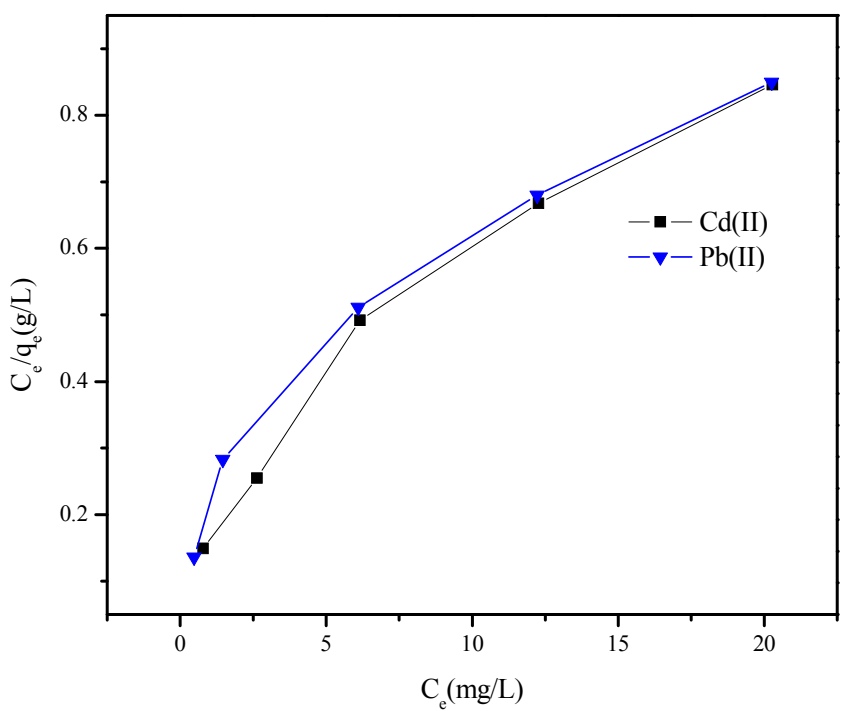

Fig. 11 - Plot of Langmuir isotherms for $\mathrm{Cd}(\mathrm{II})$ and $\mathrm{Pb}(\mathrm{II})$ adsorption on PAA-SD composite at $25^{\circ} \mathrm{C}$. 


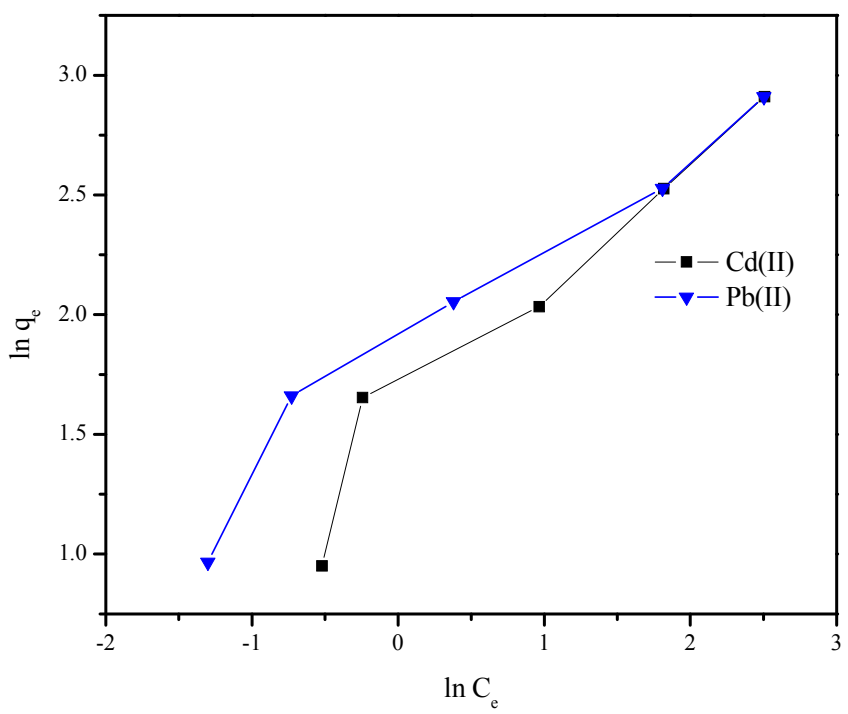

Fig. 12 - Plot of Freundlich isotherms for adsorption of $\mathrm{Cd}(\mathrm{II})$ and $\mathrm{Pb}(\mathrm{II})$ on PAA-SD composite at $25^{\circ} \mathrm{C}$.

\section{Table 2}

Comparison of isotherm constants for $\mathrm{Cd}(\mathrm{II})$ and $\mathrm{Pb}(\mathrm{II})$ ions adsorption on PAA-SD composite at different temperatures

\begin{tabular}{|c|c|c|c|c|c|c|c|}
\hline \multirow[t]{2}{*}{ Metal ion } & \multirow[t]{2}{*}{ Temperature (K) } & \multicolumn{3}{|c|}{ Langmuir's constants } & \multicolumn{3}{|c|}{ Freundlich's constants } \\
\hline & & $\underset{\left(\mathrm{mgg}^{-1}\right)}{\mathrm{q}_{\max }}$ & $\mathrm{K}_{\mathrm{L}} 10^{-2}(\mathrm{~L} / \mathrm{mg})$ & $\overline{\mathbf{R}^{2}}$ & $1 / \mathrm{n}(\mathrm{mg} / \mathrm{g})$ & $\begin{array}{c}\mathbf{K}_{\mathrm{F}} \\
(\mathrm{mg} / \mathrm{L})\end{array}$ & $\overline{\mathbf{R}^{2}}$ \\
\hline \multirow[t]{3}{*}{$\mathrm{Cd}(\mathrm{II})$} & 298 & 28.571 & 17.98 & 0.952 & 0.562 & 4.486 & 0.956 \\
\hline & 308 & 29.411 & 22.22 & 0.951 & 0.511 & 5.338 & 0.947 \\
\hline & 318 & 30.300 & 29.00 & 0.946 & 0.458 & 6.104 & 0.960 \\
\hline \multirow[t]{3}{*}{$\mathrm{Pb}(\mathrm{II})$} & 298 & 32.25 & 19.00 & 0.922 & 0.468 & 6.043 & 0.971 \\
\hline & 308 & 33.33 & 20.40 & 0.918 & 0.343 & 6.952 & 0.978 \\
\hline & 318 & 34.48 & 21.30 & 0.915 & 0.448 & 7.249 & 0.928 \\
\hline
\end{tabular}

Table 3

Comparison of adsorption capacity of PAA-SD composite with reported adsorbents

\begin{tabular}{llccc}
\hline \multicolumn{1}{c}{ Adsorbent } & Modifying agent (s) & Heavy metal & $\begin{array}{c}\mathbf{q}_{\text {max }} \\
\left(\mathbf{m g ~ g}^{-1}\right)\end{array}$ & Reference \\
\hline Rice husk & Sodium hydroxide & $\mathrm{Cd}(\mathrm{II})$ & 20.24 & 20 \\
Corncorb & Nitric acid & $\mathrm{Cd}(\mathrm{II})$ & 19.3 & 49 \\
Rice husk ash & Without any pretreatment & $\mathrm{Cd}(\mathrm{II})$ & 3.0392 & \\
\hline
\end{tabular}


Table 3 (continued)

\begin{tabular}{lllll}
\hline $\begin{array}{l}\text { Sawdust of deciduous } \\
\text { trees }\end{array}$ & No treatment & $\mathrm{Cd}(\mathrm{II})$ & 3.5 & 50 \\
Bamboo charcoal & Washed with water & $\mathrm{Cd}(\mathrm{II})$ & 12.08 & 51 \\
$\begin{array}{l}\text { Sawdust } \\
\text { Modified peanut husk }\end{array}$ & $\begin{array}{l}\text { Washed with deionized water } \\
\text { Formalin }\end{array}$ & $\mathrm{Pb}(\mathrm{II})$ & 21.05 & 52 \\
& & $\mathrm{~Pb}(\mathrm{II})$ & 29.14 & 53 \\
Meranti tree sawdust & Formaldehyde & $\mathrm{Pb}(\mathrm{II})$ & 31.95 & 54 \\
& & & \\
Empty fruit bunch & NaOH & $\mathrm{Pb}(\mathrm{II})$ & 20.00 & 26 \\
fiber & & & \\
Apricot stone & Sulphuric acid & $\mathrm{Pb}(\mathrm{II})$ & 21.38 & Present work \\
PAA-SD & Composite & $\mathbf{C d}(\mathrm{II})$ & $\mathbf{2 8 . 5 7}$ & \\
& & $\mathbf{P b}(\mathrm{II})$ & $\mathbf{3 2 . 2 5}$ & \\
\hline
\end{tabular}

\section{Adsorption thermodynamics}

The values of free energy change $\left(\Delta \mathrm{G}^{0}\right)$ for adsorption process were calculated, using the Eq. (7). ${ }^{55}$

$$
\Delta \mathrm{G}^{\mathrm{o}}=-\mathrm{RT} \ln \mathrm{K}
$$

Where $\mathrm{R}\left(8.314 \mathrm{Jmol}^{-1} \mathrm{~K}^{-1}\right)$ is universal gas constant and $\mathrm{T}(\mathrm{K})$ is the absolute temperature. The values of thermodynamic parameters are given in Table 4. The negative value of $\Delta \mathrm{G}^{\circ}$ shows the spontaneous and feasible nature of adsorption. The values of $\Delta \mathrm{H}^{\circ}$ and entropy change $\Delta \mathrm{S}^{\circ}$ can be determined using Van't Hoff equation as Eq. (8) ${ }^{56}$

$$
\begin{aligned}
& \ln \mathrm{K}=\frac{\Delta \mathrm{S}^{\mathrm{o}}}{\mathrm{R}}-\frac{\Delta \mathrm{H}^{\mathrm{o}}}{\mathrm{RT}} \\
& \Delta \mathrm{G}^{\mathrm{o}}=\Delta \mathrm{H}^{\mathrm{o}}-\mathrm{T} \Delta \mathrm{S}^{\mathrm{o}}
\end{aligned}
$$

The $\Delta \mathrm{S}^{\circ}$ and $\Delta \mathrm{H}^{\mathrm{o}}$ were calculated from the slope of and intercept of $\ln \mathrm{K}$ vs $1 / \mathrm{T}$ given in Fig. 13. The positive values of $\Delta \mathrm{H}^{\mathrm{o}}$ confirmed the endothermic nature of adsorption, while the positive values of $\Delta S^{o}$ show the high randomness on active sites during adsorption. The activation energy for adsorption of $\mathrm{Cd}(\mathrm{II})$ and $\mathrm{Pb}$ (II) ions were calculated using Arrhenius equation as Eq. (10).

$$
\ln \mathrm{K}=\ln \mathrm{A}-\frac{\mathrm{E}_{\mathrm{a}}}{\mathrm{RT}}
$$

The activation energy was calculated from the slope of plot of $\ln \mathrm{K}$ vs $1 / \mathrm{T}$ as given in Fig. 13 and was found to be $12.148 \mathrm{~kJ} \mathrm{~mol}^{-1}$ for $\mathrm{Cd}(\mathrm{II})$ and $7.165 \mathrm{~kJ} \mathrm{~mol}^{-1}$ for $\mathrm{Pb}(\mathrm{II})$. These results confirmed that the adsorption of metal ions on PAA-SD composite was physical. The physical adsorption process has energy in the range of $5-40 \mathrm{~kJ} \mathrm{~mol}^{-1}$ while chemical adsorption process has $40-800 \mathrm{~kJ}$ mol $^{-1}$ energy. ${ }^{57}$

\section{CONCLUSIONS}

A novel PAA-SD composite was synthesized and used as a cost effective adsorbent for the removal of $\mathrm{Cd}(\mathrm{II})$ and $\mathrm{Pb}(\mathrm{II})$ from aqueous solutions. Adsorption was found dependent on temperature, contact time, $\mathrm{pH}$ and initial metal ion concentration. The adsorption kinetics followed pseudo second order kinetic model. Adsorption isotherms were applied to the experimental data which fitted well with Langmuir and Freundlich isotherms. The maximum adsorption capacities, $\mathrm{q}_{\mathrm{m}}$ (from Langmuir model) $\mathrm{Cd}(\mathrm{II})$ and $\mathrm{Pb}$ (II) ions at $25{ }^{\circ} \mathrm{C}$, were $28.57 \mathrm{mg} \mathrm{g}^{-1}$ and $32.25 \mathrm{mg} \mathrm{g}^{-1}$ respectively. The activation energy values 12.148 $\mathrm{kJ} \mathrm{mol}^{-1}$ and $7.165 \mathrm{~kJ} \mathrm{~mol}^{-1}$ for $\mathrm{Cd}(\mathrm{II})$ and $\mathrm{Pb}(\mathrm{II})$ suggested physical adsorption. The thermodynamic parameters showed the exothermic, feasibility and spontaneous nature of the adsorption. The PAASD composite showed superior adsorption capacities for $\mathrm{Cd}(\mathrm{II})$ and $\mathrm{Pb}$ (II) than some adsorbent reported in literature. The cost effective nature and high adsorption capacity of PAA-SD for $\mathrm{Cd}(\mathrm{II})$ and $\mathrm{Pb}(\mathrm{II})$ rank it as a potential contender for waste-water treatments on industrial level. 


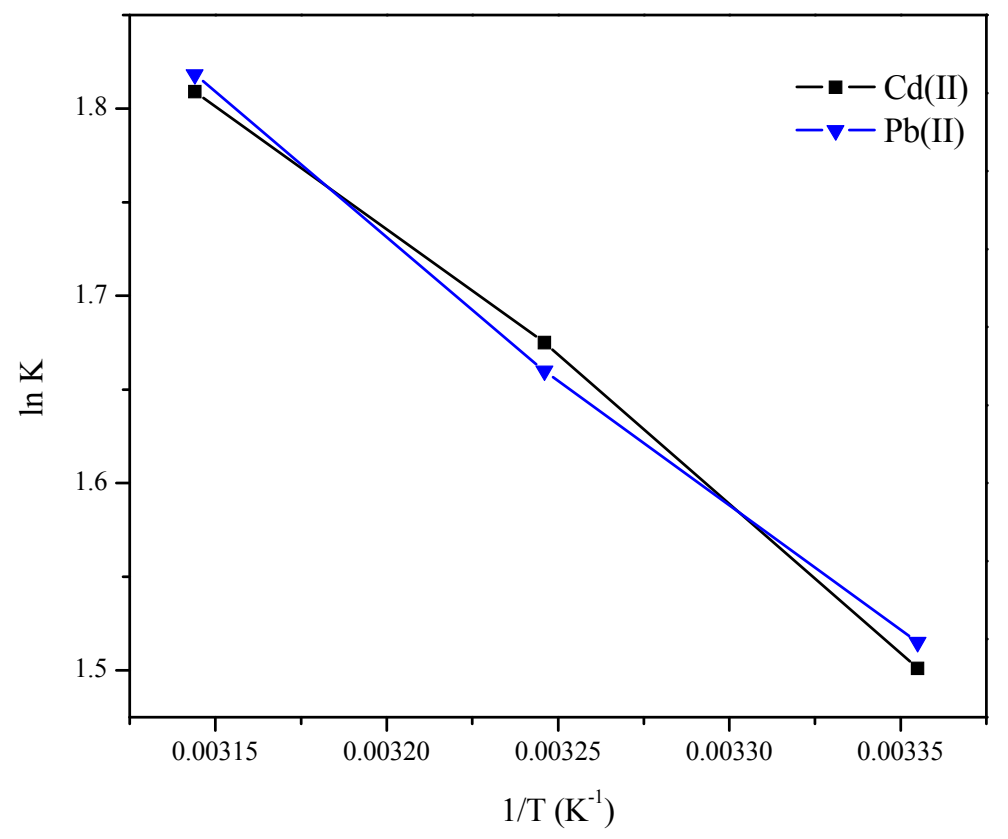

Fig. 13 - Plot of Van't Hoff equation for $\mathrm{Cd}(\mathrm{II})$ and $\mathrm{Pb}(\mathrm{II})$ ions adsorption on PAA-SD composite.

\section{Table 4}

Thermodynamics parameters for $\mathrm{Cd}(\mathrm{II})$ and $\mathrm{Pb}(\mathrm{II})$ ions adsorption on $\mathrm{PAA}-\mathrm{SD}$ composite at different temperatures

\begin{tabular}{|c|c|c|c|c|c|}
\hline Metal ion & $\begin{array}{c}\text { Temperature } \\
\text { (K) }\end{array}$ & $\begin{array}{c}\mathbf{K}_{\mathbf{F}} \\
(\mathbf{L} / \mathbf{g})\end{array}$ & $\begin{array}{c}\Delta \mathbf{H}^{\mathbf{0}} \\
\mathrm{kJmol}^{-1}\end{array}$ & $\begin{array}{c}\Delta \mathbf{S}^{\mathbf{0}} \\
\mathbf{k J m o l}^{-1} \mathbf{K}^{-1}\end{array}$ & $\begin{array}{c}\Delta \mathbf{G}^{\mathbf{0}} \\
\mathbf{k J m o l}^{-1}\end{array}$ \\
\hline \multirow[t]{3}{*}{$\overline{\mathrm{Cd}(\mathrm{II})}$} & 298 & 4.486 & 12.146 & 0.0532 & -3.718 \\
\hline & 308 & 5.338 & --- & 0.0533 & -4.289 \\
\hline & 318 & 6.104 & --- & 0.0532 & -4.782 \\
\hline \multirow[t]{3}{*}{$\mathrm{Pb}(\mathrm{II})$} & 298 & 6.043 & 7.165 & 0.0390 & -4.457 \\
\hline & 308 & 6.952 & --- & 0.0389 & -4.829 \\
\hline & 318 & 7.249 & --- & 0.0390 & -5.237 \\
\hline
\end{tabular}

\section{REFERENCES}

1. M. Hashim, S. Mukhopadhyay, J. N. Sahu and B. Sengupta, J. Environ. Manage., 2011, 92, 2355.

2. A. Demirbas, J. Hazard. Mater., 2004, 109, 221.

3. V. C. Taty-Costodes, H. Fauduet, C. Porte and A. Delacroix, J. Hazard. Mater., 2003, 105, 121.
4. V. K. Gupta, S. Agarwal and T. A. Saleh, J. Hazard. Mater., 2011, 185, 17.

5. B. Yu, Y. Zhang, A. Shukla, S. S. Shukla and K. L. Dorris, J. Hazard. Mater., 2001, 84, 83.

6. S.-H. Kim, H. Song, G. M. Nisola, J. Ahn, M. M. Galera, C. Hee Lee and W.-J. Chung, J. Ind. Eng. Chem., 2006, 12,469 . 
7. H. R. Tashauoei, S. Hashemi, R. Ardani, Z. Yavari and M. Asadi-Ghalhari, J. Saf. Environ. Health Res., 2016, 1, 11.

8. A. Pérez-Marín, V. M. Zapata, J. Ortuno, M. Aguilar, J. Sáez and M. Lloréns, J. Hazard. Mater., 2007, 139, 122.

9. B. Benguella and H. Benaissa, Water Res., 2002, 36, 2463.

10. O. Yavuz, R. Guzel, F. Aydin, I. Tegin and R. Ziyadanogullari, Pol. J. Environ. Stud., 2007, 16, 467.

11. S. N. do Carmo Ramos, A. L. P. Xavier, F. S. Teodoro, L. F. Gil and L. V. A. Gurgel, Ind. Crops. Prod., 2016, 79, 116.

12. A. M. Mahmoud, F. A. Ibrahim, S. A. Shaban and N. A. Youssef, Egypt. J. Pet., 2015, 24, 27.

13. T. Sreeprasad, S, M. Maliyekkal, K. Lisha and T. Pradeep, J. Hazard. Mater., 2011, 186, 921.

14. H. Ozaki, K. Sharma and W. Saktaywin, Desalination, 2002, 144, 287.

15. A. Dabrowski, Z. Hubicki, P. Podkościelny and E. Robens, Chemosphere, 2004, 56, 91.

16. S. Ricordel, S. Taha, I. Cisse and G. Dorange, Sep. Purif. Technol., 2001, 24, 389.

17. B. Alyüz and S. Veli, J. Hazard. Mater., 2009, 167, 482.

18. C. Xiong, L. Pi, X. Chen, L. Yang, C. Ma and X. Zheng, Carbohydr. Polym., 2013, 98, 1222.

19. U. Kumar and M. Bandyopadhyay, Bioresour. Technol., 2006, 97, 104.

20. R. Leyva-Ramos, L. Bernal-Jacome and I. AcostaRodriguez, Sep. Purif. Technol., 2005, 45, 41.

21. S. Cay, A. Uyanık and A. Özaşık, Sep. Purif. Technol., 2004, 38, 273.

22. V. C. Srivastava, I. D. Mall and I. M. Mishra, Chem. Eng. J., 2006, 117, 79 .

23. L. Semerjian, J. Hazard. Mater. 2010, 173, 236.

24. A. Ahmad, M. Rafatullah, O. Sulaiman, M. H. Ibrahim, Y. Y. Chii and B. M. Siddique, Desalination, 2009, 247, 636.

25. M. Sekar, V. Sakthi and S. Rengaraj, J. Colloid Interface Sci., 2004, 279, 307.

26. L. Mouni, D. Merabet, A. Bouzaza and L. Belkhiri, Desalination, 2011, 276, 148.

27. Q. Feng, Q. Lin, F. Gong, S. Sugita and M. Shoya, J. Colloid Interface Sci., 2004, $278,1$.

28. Y. Bulut and Z. Tez, Fresen. Environ. Bull. J., 2003, 12, 1499.

29. S. Doyurum and A. Celik, J. Hazard. Mater., 2006, 138, 22.

30. Y. Bulut, G. Akçay, D. Elma and I. E. Serhatl1, J. Hazard. Mater., 2009, 171, 717.

31. B. Nagy, A. Maicaneanu, C. Indolean, S. Burca, L. Silaghi-Dumitrescu and C. Majdik, Acta. Chim. Slov., 2013, 60, 263.

32. R. Liang and M. Liu, J. Appl. Polym. Sci., 2007, 106, 3007 .
33. M. A. Wahab, S. Jellali and N. Jedidi, Bioresour. Technol., 2010, 101, 5070.

34. M. S. Rahman and M. R. Islam, Chem. Eng. J., 2009, 149, 273

35. J. Singh, N. Mishra, S. Banerjee and Y. C. Sharma, BioResources, 2011, 6, 2732.

36. R. Huang, B. Wang, B. Yang, D. Zheng and Z. Zhang, Desalination, 2011, 280, 297.

37. C. Minakshi and S. Arya, Int. J. Adv. Res. Sci. Technol., 2014, 3, 99.

38. M. Shakirullah, I. Ahmad and S. Shah, J. Chin. Chem. Soc., 2006, 53, 1045.

39. Y. Muhammad, Y. Lu, C. Shen and C. Li, Energy Convers. Manage., 2011, 52, 1364.

40. Y. Muhammad, A. Shoukat, A. U. Rahman, H. U. Rashid and W. Ahmad, Chin. J. Chem. Eng., 2018, 26, 593.

41. D. Sud, G. Mahajan and M. P. Kaur, Bioresour. Technol., 2008, 99, 6017.

42. N. K. Amin, J. Hazard. Mater., 2009, 165, 52.

43. M. R. Moghadam, N. Nasirizadeh, Z. Dashti and E. Babanezhad, Int. J. Ind. Chem., 2013, 4, 19.

44. B. H. Hameed, D. K. Mahmoud and A. L. Ahmad, J. Hazard. Mater., 2008, 158, 65.

45. C. Fan, K. Li, J. Li, D. Ying, Y. Wang and J. Jia, J. Hazard. Mater., 2017, 326, 211.

46. Y. Sharma, U. S. Upadhyay and F. Gode, J. Appl. Sci. Environ. Sanit., 2009, 4, 21.

47. M. Rauf, S. Bukallah, F. Hamour and A. Nasir, Chem. Eng. J., 2008, 137, 238.

48. N. Wang, R. Jin, A. Omer and X. OuYang, Int. J. Biol. Macromol., 2017, 102, 232.

49. V. C. Srivastava, I. D. Mall and I. M. Mishra, Colloids Surf. A. Physicochem. Eng. Asp., 2008, 312, 172.

50. D. Božić, V. Stanković, M. Gorgievski, G. Bogdanović and R. Kovačević, J. Hazard. Mater., 2009, 171, 684.

51. F. Y. Wang, H. Wang and J. W. Ma, J. Hazard. Mater. 2010, 177, 300.

52. Q. Li, J. Zhai, W. Zhang, M. Wang and J. Zhou, J., Hazard. Mater., 2007, 141, 163.

53. A. Ahmad, M. Rafatullah, O. Sulaiman, M. H. Ibrahim, Y. Y. Chii and B. M. Siddique, Desalination, 2009, 247, 636.

54. M. M. Ibrahim, W. W. Ngah, M. Norliyana, W. W. Daud, M. Rafatullah, O. Sulaiman and R. Hashim, J. Hazard. Mater., 2010, 182, 377.

55. C. Lei, X. Zhu, B. Zhu, C. Jiang, Y. Le and J. Yu, J. Hazard. Mater., 2017, 321, 801.

56. A. Nashine and A. Tembhurkar, J. Environ. Chem. Eng., 2016, 4, 3267.

57. S. Chakravarty, A. Mohanty, T. N. Sudha, A. Upadhyay, J. Konar, J. Sircar, A. Madhukar and K. Gupta, J. Hazard. Mater., 2010, 173, 502. 
